https://helda.helsinki.fi

\title{
Lipid-modifying enzymes in oat and faba bean
}

\section{Yang, Zhen}

2017-07-04

Yang , Z , Piironen , V I \& Lampi , A-M 2017 , ' Lipid-modifying enzymes in oat and faba bean ' , Food Research International , vol. 100 , pp. 335-343 . https://doi.org/10.1016/j.foodres.2017.07.005

http://hdl.handle.net/10138/310954

https://doi.org/10.1016/j.foodres.2017.07.005

cc_by_nc_nd

acceptedVersion

Downloaded from Helda, University of Helsinki institutional repository.

This is an electronic reprint of the original article.

This reprint may differ from the original in pagination and typographic detail.

Please cite the original version. 
* Corresponding author: P.O. Box 66 (Agnes Sjöbergin katu 2), FIN-00014 Helsinki, Finland. Tel.: +358456410500

E-mail address: zhen.yang@ helsinki.fi (Z. Yang). 


\section{Abstract}

The aim was to study lipase, lipoxygenase (LOX) and peroxygenase (POX) activities in oat and faba bean samples to be able to evaluate their potential in formation of lipid-derived off-flavours. Lipase and LOX activities were measured by spectroscopy, and POX activities via the formation of epoxides. An ultra-high performance liquid chromatography method was developed to study the formation of fatty acid epoxides. The epoxides of esters were measured by gas chromatography. Mass spectroscopy was used to verify the identity of the epoxides. Both oat and faba bean possessed high lipase activities. In faba bean, LOX catalysed the formation of hydroperoxides, whose break-down products are the likely cause of off-flavours. Since oat had low LOX activity, autoxidation is needed to initiate lipid oxidation. Oat had high POX activity, which is able to convert hydroperoxides to epoxy and hydroxy fatty acids that could contribute significantly to offflavours. POX activity in the faba bean was low. Thus, in faba bean volatile lipid oxidation products could rapidly be formed by LOX, whereas in oat reactions are slower due to the need of autoxidation prior to further reactions.

Keywords: Oat; Faba bean; Lipase; Lipoxygenase; Peroxygenase; Off-flavour; Analysis of fatty acid epoxides 


\section{Introduction}

Oat (Avena sativa) and faba bean (Vicia faba L.) are good candidates when new sources of plant proteins and contributors to the sustainable development in agricultural and food systems are looked for. Oat has long been recognised as a valuable source of many nutrients for humans and animals (Decker, Rose, \& Stewart, 2014). The faba bean is one of the leading grain legumes in the world, and it is mainly used as a rich source of protein, but it also contains lots of starch (Crépon et al., 2010; Lizarazo et al., 2015). One problem associated with using plant proteins in foods is formation of lipid-derived off-flavours, which diminish the consumer acceptance of these products. Some of the off-flavours develop immediately through the action of enzymes, whereas some occur only after long-term storage. To control enzymatic reactions, the inactivation of lipid-modifying enzymes by heat treatment is essential (Decker et al., 2014; Jiang et al., 2016; Lehtinen, Kiiliäinen, Lehtomäki, \& Laakso, 2003; Roland, Pouvreau, Curran, van de Velde, \& de Kok, 2017). However, overly severe treatments should be avoided because they may cause problems in the sensory and technological properties of the products.

One lipid-modifying enzyme is lipase, which liberates free fatty acids (FFAs) from their esters. The liberated fatty acids may be oxidised chemically or enzymatically into odourless and tasteless hydroperoxides. The endogenous lipases will start hydrolysing acyl lipids as soon as the seed structure breaks down and the enzyme comes into contact with its substrates. The function of lipases during the processing and storage of oat has been well characterised (Decker et al., 2014; Lehtinen et al., 2003). A lipase has also been isolated from small faba bean (Dundas, Henderson, \& Eskin, 1978) and a sequential hydrolytic pathway has been proposed (Henderson, Shambrock, \& Eskin, 1981). However, little is known of lipase activity and its impact in faba bean. 
Lipoxygenase (LOX) is the enzyme responsible for the formation of hydroperoxides, which in turn can further react to form volatile off-flavours, such as hexanal, or non-volatile products, such as oxoacids and dimers (Gardner, 2003) through several chemical and enzymatic pathways. LOX activity in legumes is regarded as responsible for the undesirable "beany flavour" through the break-down of its hydroperoxide products (Gardner, 2003; Roland et al., 2017). The faba bean has been categorised as possessing medium-level LOX activity among legumes (Chang \& McCurdy, 1985). Two LOX isoenzymes have been characterised from the faba bean (Clemente, Olías, \& Olías, 2000). Much less is known about LOX activities in cereal grains. In a review paper, Lehtinen and Kaukovirta-Norja (2011) reported that LOX activity in oat was lower than in, for example, wheat and barley.

Peroxygenase (POX) catalyses the hydroperoxide-dependent conversion of unsaturated fatty acids into non-volatile flavour compounds, namely epoxy and hydroxy fatty acids (Hamberg \& Hamberg, 1996). The POX pathway begins when one of the oxygens of a fatty acid hydroperoxide is transferred to an unsaturated fatty acid, yielding a hydroxy fatty acid and an epoxy fatty acid. These compounds have been suggested to be responsible for the formation of the bitter taste in aged oat products (Hamberg \& Hamberg, 1996; Doehlert, Angelikousis, \& Vick, 2010). POX has been isolated from oat seeds (Hamberg \& Hamberg, 1996). Currently, oat POX has important potential in the production of fatty acid epoxides in the chemical industry (Piazza, Nuñez, \& Foglia, 2003). Hamberg and Fahlstadius (1992) have also observed hydroperoxide-dependent epoxidation of unsaturated fatty acids in faba bean. However, little research has been done on the POX activity in either oat or faba bean foods. Although detrimental effects of lipase on oat lipids and of LOX on faba bean lipids are well described (Piazza, Bilyk, Brower, \& Haas, 1992; Clemente et al., 2000; Lehtinen \& Kaukovirta- 
Norja, 2011), there is very little knowledge on the overall effects of the lipid-modifying enzymes on oat and faba bean products, and the levels and variation of enzyme activities present in the seeds. Understanding and controlling the lipid-modifying enzymes is essential to prolong the shelf life of the products and raise consumer acceptance towards them.

The aim of the study was to understand the potential of lipase, LOX and POX activities present in oat and faba bean seeds and to evaluate their possible contribution to the formation of compounds related to lipid-derived off-flavours. The enzyme activities were studied in seeds from several cultivars and growing seasons. Lipase and LOX activities were measured using spectrophotometric methods, whereas methods to study POX activities in various substrates were developed.

\section{Materials and methods}

\subsection{Chemicals and standards}

Substrates for the enzyme activity analyses, including methyl oleate (purity $>99 \%$ ), methyl linoleate (purity > 99\%), methyl linolenate (purity > 99\%), triolein (purity > 99\%), oleic acid (purity $>99 \%$ ), linoleic acid (purity $>99 \%$ ), linolenic acid (purity $>99 \%$ ), as well as the internal standards, nonadecanoic acid (purity $>99 \%$ ) and its methyl ester (purity $>99 \%$ ), were purchased from Nu-Check Prep, Elysian, MN, USA. Cumene hydroperoxide (80\%) and para-nitrophenyl butyrate (purity $\geq 98 \%$ ) were obtained from Sigma-Aldrich (St. Louis, USA). The epoxy stearic acid used for the quantification of epoxy fatty acids was obtained from Santa Cruz Biotechnology ${ }^{\circledR}$ (Texas, USA). All other reagents were purchased from Sigma-Aldrich and Merck (Darmstadt, Germany). Water was purified using the Milli-Q system (Millipore Corp., Bedford, MA, USA). 9

\subsection{Oat and faba bean samples}


101 Commercial oat flour from the Raisio Group (Nokia, Finland) and faba bean flour milled from the

102

103 cultivar "Kontu", grown in the year 2011 at the Viikki Experimental Farm (Lizarazo et al., 2015), were used as in-house reference samples to verify the analytical level of the measurements. The oat flour was used for POX activity measurements, and the faba bean flour for lipase and LOX activity measurements. Oat grain samples (cultivars Akseli, Alku, Meeri and Steinar) were provided by Boreal Plant Breeding Ltd. (Jokioinen, Finland). They were grown in the cultivation years 2012, 2013 and 2014 in the same area in southern Finland and were stored at $10-15^{\circ} \mathrm{C}$. The faba bean samples (cultivars Kontu, Alexia, Fatima and SSNS-1) were obtained from the Viikki Experimental Farm of the University of Helsinki in southern Finland from three cultivation years. Samples from the years 2011 and 2015 were stored at $5{ }^{\circ} \mathrm{C}$, while the samples from the year 2010 were stored at room temperature (RT). Detailed information on the faba bean samples and weather conditions was given by Lizarazo et al. (2015). All seed samples were milled using a Centrifugal Mill ZM200 (Retsch, Haan, Germany) fitted with a $0.5-\mathrm{mm}$ sieve, after which the samples were immediately transferred to a freezer and stored at $-20{ }^{\circ} \mathrm{C}$ before analysis.

\subsection{Enzyme extraction from oat and faba bean flour}

Enzymes were extracted from the milled oat and faba bean samples. The flours $(2.5 \mathrm{~g})$ were mixed with $23 \mathrm{ml}$ of cold $0.1 \mathrm{M}$ potassium phosphate buffer ( $\mathrm{pH}$ 6.7) in centrifugation tubes, vortexed (4 $\mathrm{x}$ $10 \mathrm{~s}$ ) and kept on ice for $1 \mathrm{~h}$. The slurries were centrifuged at $4{ }^{\circ} \mathrm{C}$ for $10 \mathrm{~min}$ at $9000 \mathrm{x} \mathrm{g}$ (Sorvall RC5C, SLA-1500 rotor), the sediments were discarded and the supernatants were centrifuged for another $10 \mathrm{~min}$. The supernatants were kept on ice before being used for enzyme activity analyses. Each sample was extracted in duplicate and one in-house reference sample was included in each extraction batch. All enzyme activity measurements were done in triplicate from each extract.

\subsection{Lipase activity measurement}


Lipase activity was measured using a spectrophotometric method with para-nitrophenyl butyrate as a substrate (Brunschwiler, Heine, Kappeler, Conde-Petit, \& Nyström, 2013). The reaction was initiated by adding sample extracts into fresh substrate solutions of $2 \mathrm{mM}$ para-nitrophenyl butyrate in $50 \mathrm{mM}$ potassium phosphate buffer containing $0.1 \%$ Triton $\mathrm{X}-100(\mathrm{pH} 8.0)$. To achieve a minimal slope (dA/min of 0.03$), 20 \mu l$ of faba bean extract and $80 \mu 1$ of oat extract were mixed with the substrate solution (total volume of $1.00 \mathrm{ml}$ ). The increase in the absorption at $405 \mathrm{~nm}$ during $150 \mathrm{~s}$ was measured with the ultraviolet spectrometer (Lambda 25 UV/Vis, Perkin Elmer Inc., USA). The molar extinction coefficient value of $16.05 \mathrm{mM}^{-1} \mathrm{~cm}^{-1}$ for hydrolysed para-nitrophenol was used to calculate the results. Lipase activity was given as $\mu \mathrm{mol} \mathrm{min}^{-1} \mathrm{~g}^{-1}$ flour.

\subsection{LOX activity measurement}

LOX activity was measured by a spectrophotometric method using linoleic acid as the substrate (Jiang et al., 2016). For the LOX assays, $200 \mu \mathrm{l}$ of the substrate solution with $10 \mathrm{mM}$ of linoleic acid, $200 \mu \mathrm{l}$ of the sample extracts and $2.6 \mathrm{ml}$ of $0.1 \mathrm{M}$ potassium phosphate buffer (pH 6) were mixed and incubated for $3 \mathrm{~min}$ at $30{ }^{\circ} \mathrm{C}$ in a water bath. The reaction was stopped by adding $3 \mathrm{ml}$ of $0.1 \mathrm{~N} \mathrm{KOH}$ solution and the absorbances were measured at $234 \mathrm{~nm}$ (Lambda $25 \mathrm{UV} / \mathrm{Vis}$, Perkin Elmer Inc., USA). The results were calculated using the molar absorptivity of conjugated dienes $(\varepsilon=26000 \mathrm{l} / \mathrm{mol} \mathrm{cm})$. The LOX activity was expressed as $\mathrm{mmol} \mathrm{min}^{-1} \mathrm{~g}^{-1}$ flour.

\subsection{Method development for POX activity measurement}

The POX activity was studied by measuring epoxide formation. FFAs, their methyl esters and triolein were used as substrates to observe the specificities of the enzyme in the oat and faba bean samples. Two methods were developed, because epoxides of esters could be analyzed by GC whereas it was not applicable to epoxides of free fatty acids, for which an UHPLC method was developed. 
153

Methyl oleate, methyl linoleate and methyl linolenate were used as methyl ester substrates for POX. Aliquots of $435 \mu \mathrm{l}$ of mixtures containing one of the substrates (ca. $3 \mathrm{mg} / \mathrm{ml}$ ) and the internal standard, methyl nonadecanoate $(1.4 \mathrm{mg} / \mathrm{ml})$ in heptane, were first evaporated under $\mathrm{N}_{2}$ at $35^{\circ} \mathrm{C}$, and then the residues were dissolved in $350 \mu \mathrm{l}$ of $1 \%$ Tween 20 in Milli-Q water by vortexing. To the substrate solutions $1.75 \mathrm{ml}$ of $100 \mathrm{mM}$ HEPES at $\mathrm{pH} 7.0,900 \mu \mathrm{l}$ of Milli-Q water and $500 \mu \mathrm{l}$ of the sample extracts were added. To start the enzymatic reaction, $7 \mu 1$ of $8 \%$ cumene hydroperoxide diluted in ethanol was added and the tubes were mixed by inverting with a rotator for $1 \mathrm{~h}$ at RT, after which the reaction was stopped by adding $5 \mathrm{ml}$ of methanol. The lipids were extracted twice with $10 \mathrm{ml}$ of diethyl ether and the extracts were washed with $5 \mathrm{ml}$ of saturated $\mathrm{NaCl}$ in Milli-Q water. Aliquots of $10 \mathrm{ml}$ were dried under $\mathrm{N}_{2}$ evaporation at $35^{\circ} \mathrm{C}$. The residues were immediately re-dissolved into $1 \mathrm{ml}$ of heptane. To study triolein as the substrate, the assay was carried out following the same steps as mentioned above, except that the final dried residues were re-dissolved into $1.5 \mathrm{ml}$ of heptane, after which the substrates and the products were methylated by alkaline transesterification (Christie, 1993).

Finally, fatty acid methyl esters and their epoxides were analysed by GC. A GC-FID (Agilent $6890 \mathrm{~N}$, USA $)$ equipped with a fused silica capillary column Omegawax ${ }^{\mathrm{TM}} 1250(30 \mathrm{~m} \times 0.25 \mathrm{~mm} \times$ $0.25 \mu \mathrm{m}$, SUPELCO $^{\circledR}$, Bellefonte, USA) was used for quantitative analysis, and a GC (HP 6890 series, Agilent Technologies Inc., Wilmington, DE, USA) with an MS detector (Agilent 5973 Network, Agilent Technologies Inc., Wilmington, DE, USA) equipped with the same capillary column was used for the identification of the epoxides. In the GC-FID analysis, helium was used as a carrier gas at a flow rate of $1.1 \mathrm{ml} / \mathrm{min}$ and $1-\mu 1$ samples were injected in a split mode $(1: 15)$ at $240{ }^{\circ} \mathrm{C}$. The oven temperature was programmed to increase from $160{ }^{\circ} \mathrm{C}$ (with a 1-min initial hold) 
with a $4{ }^{\circ} \mathrm{C} / \min$ to $240{ }^{\circ} \mathrm{C}$ (with a 15 -min final hold). The GC-MS analysis was conducted similarly, except that the split ratio was 1:20, and the oven temperature was programmed to increase from $150{ }^{\circ} \mathrm{C}$ (with a 2-min initial hold) with a $4{ }^{\circ} \mathrm{C} / \mathrm{min}$ to $240{ }^{\circ} \mathrm{C}$ (with a 20 -min final hold). The ionisation energy of MS was $70 \mathrm{eV}$, the ion source temperature was $230{ }^{\circ} \mathrm{C}$ and the mass range of $m / z, 40-450$ was scanned. The epoxides and substrates were quantified using an internal standard method and assuming equal FID responses for all compounds. Finally, the results were expressed as a $\%$ of the epoxide(s) formed and as a $\%$ of the substrate residues left from each substrate.

\subsubsection{UHPLC-ELSD and UHPLC-Q-TOF methods for studying free fatty acids as substrates}

FFAs at three unsaturation levels - oleic acid, linoleic acid and linolenic acids - were used as substrates (ca. $3 \mathrm{mg} / \mathrm{ml}$ ) for POX. Nonadecanoic acid used as an internal standard $(3.16 \mathrm{mg} / \mathrm{ml})$ was included in the substrate mixtures. The mixtures were incubated, and thereafter the lipids were extracted with diethyl ether, as described in Section 2.6.1. After evaporation, the residues were immediately re-dissolved into $1 \mathrm{ml}$ of isopropanol and $1 \mathrm{ml}$ of methanol. Finally, the fatty acids and their epoxides were analysed by UHPLC with a method developed in this study.

For the quantification of the lipids, a UHPLC-ELSD instrument was used, and for the identification of the epoxides, a UHPLC-Q-TOF instrument was used. The UHPLC-ELSD instrument consisted of a UHPLC (Waters Acquity, Milford MA, USA) coupled with an ELSD detector (Waters Acquity, Milford, MA, USA). The FFAs and epoxides were separated with a reversed-phase Acquity UPLC ${ }^{\circledR}$ HSS T3 column $(1.8 \mu \mathrm{m}, 2.1 \times 150 \mathrm{~mm}$, Waters, Ireland $)$ using gradient elution consisting of a mixture of Milli-Q $\mathrm{H}_{2} \mathrm{O}$ and $0.05 \%$ acetic acid (solvent $\mathrm{A}$ ) and of methanol with $0.05 \%$ acetic acid (solvent $\mathrm{B}$ ) at a flow rate of $0.3 \mathrm{ml} / \mathrm{min}$ at $30{ }^{\circ} \mathrm{C}$. The 15 -min elution program with the two solvents (solvent A:solvent B, vol\%:vol\%) was as follows: 0-0.5 min (25:75); 0.5-9 $\min (25: 75$ to $2: 98) ; 9-12 \min (2: 98) ; 12-12.5 \min (2: 98$ to $25: 75)$; and $12.5-15 \min (25: 75)$. The 
ELSD drift tube temperature was set to $50{ }^{\circ} \mathrm{C}$ and the gain to 500 . Nebulisation was performed with filtered air at 40.0 psi, and the cone and desolvation gas flows were 100 and 1000 1/Hr, respectively. The epoxide contents were calculated based on the standard curves of the second-order equations made from the 9,10-epoxystearic acid standard and internal standard nonadecanoic acid. The results were expressed as a $\%$ of the epoxide(s) formed and as a $\%$ of the substrate residues left from each substrate.

The identification of the fatty acid epoxides was carried out in a negative ion mode on a UHPLC-QTOF (Acquity I class, Milford, MA, USA) with an electrospray ionisation (ESI) interface, coupled with a SYNAPT G2-Si Mass Spectrometer. The column, eluents and elution program were the same as in the UHPLC-ELSD instrument. The scanning was carried out in the mass range of $m / z 50$ 1200. The instrumental settings were as follows: capillary voltage $2.5 \mathrm{kV}$, sampling cone voltage 40 $\mathrm{V}$, source offset $80 \mathrm{~V}$, source temperature $100{ }^{\circ} \mathrm{C}$, desolvation temperature $500{ }^{\circ} \mathrm{C}$, desolvation gas flow 1000 l/h, nebuliser gas flow 6.2 bar, cone gas flow 100 l/h, trap collision energy $4 \mathrm{eV}$, ramp for MS/MS trap collision energy $10-70 \mathrm{eV}$, trap gas flow $2 \mathrm{ml} / \mathrm{min}$ and a scan time of $0.3 \mathrm{~s}$.

\subsection{Statistical analysis}

All results were expressed as mean values \pm standard deviations of six replicate samples. Statistical analysis was performed using SPSS version 22 (IBM SPSS Statistics, USA). A value of $p<0.05$ was considered statistically significant. To study the effects of cultivars and sample years and their interactions on the enzyme activities, the results were subjected to a two-way analysis of variance (ANOVA), and thereafter to Tukey tests to identify homogenous groups of samples. Figures were drawn using OriginPro 8.6 (OriginLab Corporation, USA).

\section{Results and discussion}




\subsection{Lipase and lipoxygenase activities in oat and faba bean}

Both the oat and faba bean samples had significant lipase activities when measured using paranitrophenyl butyrate as the substrate. In oat, the activities ranged between $0.41 \pm 0.02$ and $0.77 \pm$ $0.03 \mu \mathrm{mol} \mathrm{min} \mathrm{m}^{-1} \mathrm{~g}^{-1}$ flour (Fig. 1a), while in faba bean, they ranged between $4.44 \pm 0.34$ and $7.51 \pm$ $0.44 \mu \mathrm{mol} \min ^{-1} \mathrm{~g}^{-1}$ flour (Fig. 1b). In both species, the activities varied almost two-fold among cultivars and samples from different years. The activity in the faba bean samples was ten-fold that of the oat samples. Lipase activity and its impact on oat have been well characterised (Decker et al., 2014; Lehtinen et al., 2003; Piazza et al., 1992), while only the presence and the basic characteristics of the enzyme in faba bean have been identified (Dundas et al., 1978; Henderson et al., 1981). The faba bean in-house reference sample gave a stable activity value of $6.72 \pm 0.12 \mu \mathrm{mol}$ $\min ^{-1} \mathrm{~g}^{-1}$ flour $(n=13)$, showing that the level of analysis was stable and that the results could be compared throughout the study.

In the oat samples, there were differences in lipase activity among the cultivars (ANOVA, $F_{3.60}=$ 125.8, $p<0.05$ ) and the cultivars were divided into three homogenous groups (Tukey HSD, $p<$ 0.05). The lowest lipase values were found in cultivar Alku, with an average of $0.54 \pm 0.11 \mu \mathrm{mol}$ $\min ^{-1} \mathrm{~g}^{-1}$ flour, while the highest occurred in cultivar Akseli, with an average of $0.71 \pm 0.08 \mu \mathrm{mol}$ $\min ^{-1} \mathrm{~g}^{-1}$ flour. Ekstrand et al. (1992) found a comparable variation in lipase activity among three cultivars, which ranged 220-268 U/g, but also greater variations have been found (Miller, Fulcher, \& Altosaar, 1989; Hu, Wei, Ren, \& Zhao, 2009). The lipase activities from the oat samples from 2012-2014 were also different (Anova, $F_{2.60}=553.6, p<0.05$ ) and samples from each year differed from the others (Tukey HSD, $p<0.05$ ). Lipase activities increased from 2012 to 2014, resulting in average values of $0.48 \pm 0.08,0.64 \pm 0.10$ and $0.72 \pm 0.05 \mu \mathrm{mol} \mathrm{min}^{-1} \mathrm{~g}^{-1}$ flour, respectively. It may indicate that long-term storage could have negatively influenced the activity. In addition, the growing and harvesting conditions in different years might have had an effect. However, the trend 
among the sample years was not always similar and there was a statistically significant interaction between the cultivars and sample years (Anova, $F_{6.60}=28.7, p<0.05$ ). For instance, the activity in cultivar Akseli was higher in samples from year 2013 than from year 2014. In summary, the cultivar and the sample year were observed to have an effect on the oat lipase activity.

For faba bean lipase activities, there were significant differences among the cultivars (Anova, $F_{3.60}$ $=259.1, p<0.05)$ (Fig. 1b) and all the cultivars differed from each other (Tukey HSD, $p<0.05$ ). The highest activities were found in cultivar Kontu, with an average of $7.18 \pm 0.45 \mu \mathrm{mol} \mathrm{min} \mathrm{g}^{-1}$ flour, and the lowest in cultivar Alexia, with an average of $4.54 \pm 0.28 \mu \mathrm{mol} \mathrm{min}^{-1} \mathrm{~g}^{-1}$ flour. The lipase activities for cultivars Fatima and SSNS-1 were $6.85 \pm 0.23$ and $6.22 \pm 0.29 \mu \mathrm{mol} \mathrm{min} \mathrm{g}^{-1}$ flour, respectively. There was more variation in lipase activities among the faba bean cultivars than among the oat cultivars. The activities in the faba bean samples were not statistically significantly different among different cultivation years (Anova, $F_{2.60}=2.4, p>0.05$ ), unlike they varied in oat. The average lipase activity values for the faba bean samples were $6.16 \pm 1.10,6.28 \pm 1.11$ and 6.09 $\pm 0.94 \mu \mathrm{mol} \mathrm{min} \mathrm{g}^{-1}$ flour for cultivation years 2010, 2011 and 2015, respectively. Large variations within the years further support that the main effect in the variation among the faba bean samples was from the cultivar. The very high lipase activities and the high variation among the faba bean cultivars found in this study are to be taken into account when processing faba bean, because without inactivating the lipases, TAGs and other acyl lipids are prone to lipolysis as soon as the intact seed structures are broken. It should be recognised that the actual lipase activities towards faba bean lipids might be lower, as the faba bean lipase was earlier shown to be more active towards esters of short-chain fatty acids than of vegetable oils (Dundas et al., 1978), and in this study, the substrate was a butyric ester. Oat lipase, on the other hand, has substrate specificity to long chain fatty acids such as oleic, linoleic and linolenic acids (Piazza et al., 1992). 
LOX activities were observed only in the faba bean samples (Fig. 1c), whereas in the oat samples, the activity could not be measured. The presence of LOX in faba bean, as in other legumes, is generally acknowledged (Gökmen, Bahceci, \& Acar, 2002; Hildebrand \& Kito, 1984), and minor LOX activities have been found in oat seeds (Lehtinen \& Kaukovirta-Norja, 2011). LOX activities among the faba bean samples ranged from $0.219 \pm 0.009$ to $0.330 \pm 0.004 \mathrm{mmol} \mathrm{min}^{-1} \mathrm{~g}^{-1}$ flour (Alexia 2011 and 2010). The levels of LOX activity found in this study were comparable to the level (0.44 mmol $\mathrm{min}^{-1} \mathrm{~g}^{-1}$ flour) that was found previously in Finland (Jiang et al., 2016). The faba bean in-house reference sample, gave a LOX activity value of $0.33 \pm 0.01 \mathrm{mmol} \mathrm{min}^{-1} \mathrm{~g}^{-1}$ flour $(n=$ 9). Therefore, the analysis level during this study was stable and the results could be compared.

There were significant differences in the LOX activities of faba bean cultivars (Anova, $F_{3.60}=50.2$, $p<0.05$ ) and three homogenous groups among the cultivars could be determined (Tukey HSD, $p<$ 0.05). LOX values for cultivars Kontu and Fatima were the highest, with average values of $0.309 \pm$ 0.027 and $0.295 \pm 0.008 \mathrm{mmol} \mathrm{min}^{-1} \mathrm{~g}^{-1}$ flour, respectively, while the lowest average value was for cultivar Alexia at $0.274 \pm 0.058 \mathrm{mmol} \mathrm{min}^{-1} \mathrm{~g}^{-1}$ flour. Although statistically significant differences among the cultivars were observed, the value for Alexia was only $11 \%$ lower than those of Kontu and Fatima. Comparably, the variation in LOX activities among three faba bean cultivars was only $<10 \%$ (Chang \& McCurdy, 1985). The sample year had a significant effect on the LOX activity of the faba bean samples (Anova, $F_{2.60}=34.2, p<0.05$ ) and the samples from the year 2011 produced lower values of $0.278 \pm 0.040 \mathrm{mmol} \mathrm{min}^{-1} \mathrm{~g}^{-1}$ flour than those from the years 2010 and 2015 at $0.299 \pm 0.032$ and $0.300 \pm 0.029 \mathrm{mmol} \mathrm{min}^{-1} \mathrm{~g}^{-1}$ flour, respectively (Tukey HSD, $p<0.05$ ). Yet the average difference among the years was only $7 \%$. However, the interaction between the cultivar and the year was statistically significant (Anova, $F_{6.60}=72.8, p<0.05$ ), with cultivar Alexia having the greatest variation and the cultivars Kontu and Fatima being the most stable ones. The highest LOX activity in Alexia was 50\% greater than the lowest activity that was found, whereas in Kontu and 
301 Fatima, the differences were only 15\%. In conclusion, there is LOX activity in faba bean, and the activity is affected both by the cultivar and the sample year as well as their interactions.

\subsection{Analysis of epoxides from fatty acid methyl esters}

All the fatty acid methyl esters studied could be converted to epoxides by oat POX, and these epoxides were used to identify epoxides isolated from esterified fatty acids. Methyl oleate, linoleate and linolenate and their epoxides were well separated by the GC-FID method (Fig. 2, combined from the chromatograms of the three substrates).To identify the epoxides, relative retention times $\left(R_{r}\right)$ and selected fragments were obtained by the GC-MS method (Table 1). The $R_{r}$ values of the epoxides were 1.332-1.423. Thus, the later eluted epoxides were clearly separated from the earlier eluted fatty acids with $\mathrm{R}_{\mathrm{r}}$ values of $0.913-1.038$.

The epoxides of the fatty acid methyl esters decomposed during ionisation to numerous fragments and the molecular ions $\left(\mathrm{M}^{+}\right)$could hardly be detected. The only epoxide that was built up from methyl oleate was identified as methyl 9,10-epoxyoctadecanoate with two major fragments built up after $\alpha$-scissions to the epoxide group (Table 1; Fig. 2), as also presented by Christie (2014). Most of the fragments of epoxides from methyl linoleate and linolenate were built up after cleavage of the methanol group and $\alpha$-scission to the epoxide group followed by rearrangements. Two epoxides were formed from methyl linoleate (Fig. 2). The first eluting epoxide was identified as methyl 12,13-epoxy-octadec-9-enoate and the second as methyl 9,10-epoxy-octadec-12-enoate (Table 1;

Fig 2). Both of them produced the fragment of $\mathrm{m} / \mathrm{z} 279$ characteristic for the cleavage of the methanol group, and more specific fragments of, e.g. $\mathrm{m} / \mathrm{z} 207$ and 168 which indicated the position of the epoxide group (Table 1). The mass spectra obtained had similar fingerprints that have been found earlier (Christie, 2014; Meesapyodsuk \& Qiu, 2011). Epoxides produced from methyl linolenate could not be fully separated from each other by GC and the mixture of epoxides resulted 
in a wide GC peak producing lots of fragment ions (Table 1; Fig. 2). No di-epoxy fatty acid methyl esters were observed. Using the $\mathrm{R}_{\mathrm{r}}$ values from the GC/MS analyses, the epoxides from different fatty acid methyl esters could be identified via GC/FID analysis and used for the quantification of epoxide formation in POX assays.

\subsection{Analysis of epoxides from free fatty acids}

All the FFAs and their epoxidation products could be separated from each other and from the internal standard nonadecanoic acid within 15 min using a reversed-phase UHPLC method, except for the isomeric products from linolenic acid that co-eluted (Fig. 3). With the UHPLC-Q-TOF instrument, the $\mathrm{R}_{\mathrm{r}}$ values of the epoxides were 0.532-0.649 and for the FFAs 0.732-0.869 (Table 1). In both cases, the more unsaturated an epoxide or a FFA was, the earlier it eluted. The epoxidation products were identified by UHPLC-Q-TOF with ESI in the negative mode, which produced deprotonated molecular ions $[M-\mathrm{H}]^{-}$as precursor ions. Characteristic fragments of $m / z>$ 150 were selected to structural identification of regio-isomers (Table 1). Each epoxide produced a fragment that was 18 mass units less than its precursor ion $\left[M-\mathrm{H}-\mathrm{H}_{2} \mathrm{O}\right]^{-}$, verifying a loss of water from all the epoxide precursor ions during fragmentation. Only mono-epoxy fatty acids were formed during incubation.

One epoxide was found from oleic acid, and it was identified as 9,10-epoxystearic acid based on precursor ions and fragments formed after scission of the carbon-carbon bond of the epoxide group (Table 1; Fig. 3). Similar mass spectra were obtained from the standard used in this study and also in an earlier study using HPLC-ESI-MS (Orellana-Coca, Adlercreutz, Andersson, Mattiasson, \& Hatti-Kaul, 2005). Two epoxides were found to be built up from linoleic acid and were identified as 12,13-mono-epoxy-9-octadecenoic acid and 9,10-mono-epoxy-12-octadecenoic acid (Table 1, Fig. 3). The position of the epoxy group was deduced based on the scission of the carbon-carbon of 
the epoxide and the position of the double bond on the cleavage of the carbon-carbon bond on the side of the double bond (Orellana-Coca et al., 2005; Murphy, 2015).

Only one linolenic acid epoxide peak with three poorly separated isomers was present when using UHPLC-Q-TOF. There was one single precursor ion from the mono-epoxide octadecadienoic acid isomers, while it decomposed into several negative fragment ions (Table 1, Fig. 3). After studying the fragments as was done with epoxides from linoleic acid, the first one was identified as 9,10mono-epoxy-12,15-octadecadienoic acid epoxide and the second as 15,16-mono-epoxy-9,12octadidecenoic acid. The third was tentatively identified as 12,13-mono-epoxy-9,15-octadidecenoic acid. The elution order of the three epoxides presented here is in line with the elution order presented by Orellana-Coca et al. (2005).

In summary, as the newly developed UHPLC method could reliably separate the epoxides from the fatty acids (Fig. 3), the UHPLC-ELSD method could be used to quantify the formation of the epoxides of fatty acids and used to study POX activity in the extracts.

\subsection{Peroxygenase activity and substrate specificities in oat and faba bean}

POX activity measurements in oat and faba bean using cumene hydroperoxide as the oxygen donor on different lipid substrates and analysed via the formation of epoxides showed great differences between the species. The oat samples had high activity whereas no activity was found in the faba bean samples. In earlier studies, POX or epoxygenase activity has been found in both oat (e.g. Hamberg \& Hamberg, 1996) and faba bean preparates (Hamberg \& Fahlstadius, 1992), but its products have only been studied in oat seeds and flours (Doehlert et al., 2010). The oat in-house reference sample gave repeatable results using methyl oleate when studying fatty acid esters as substrates, and using oleic acid when studying FFAs as substrates. The methyl-9,10- 
epoxyoctadecanoate production was $14.2 \% \pm 1.2 \%(n=18)$ and 9,10-epoxyoctadecanoic acid production was $54.9 \% \pm 3.0 \%(n=18)$, which means that the analysis levels using both classes of substrates and analytical methods were stable and the results within the classes could be compared. To our knowledge, this study is the first one to compare POX activities in different oat cultivars and sample years, as well as to use formation of epoxides as the indicator of POX activity.

The POX in the oat samples could use fatty acid methyl esters and FFAs as substrates whereas no epoxides were built up from triolein (Tables 2 and 3), which means that the TAGs were not suitable substrates for oat POX. In line with our results, FFAs and methyl esters have been reported as the more preferred substrates for oat POX than phospholipids (Meesapyodsuk et al., 2011). However, as oat contains lipase activity, unsaturated fatty acids from acylglycerols may be subjected to peroxygenation after being hydrolysed. The proportion of epoxides measured after incubation varied from $19.1 \%-42.0 \%$ in methyl esters and from $34.6 \%-70.7 \%$ in fatty acids, indicating that oat POX preferred FFAs as substrates over fatty acid methyl esters. When comparing the level of unsaturation of the substrate on the formation of epoxides, there were statistically significant differences both among fatty acid methyl esters $\left(F_{2.213}=43.3, p<0.05\right)$ and fatty acids $\left(F_{2.213}=\right.$ $11.9, p<0.05)$. With both classes of substrates, the mono- and diunsaturated substrates formed a homogenous group, from which the triunsaturated substrates differed (Tukey HSD, $p>0.05$ ). The average proportions for epoxide formation for the methyl esters were $32.5 \% \pm 6.2 \%, 33.0 \% \pm 5.2 \%$ and $23.6 \% \pm 1.7 \%$, and for the fatty acids, $59.9 \% \pm 5.4 \%, 58.0 \% \pm 6.4 \%$ and $41.4 \% \pm 3.6 \%$ in order of increasing unsaturation. One possible reason for the lower epoxide values with methyl linolenate and linolenic acid could be that the epoxides might have reacted further or that the substrate was oxidised via some other mechanism. When summing up the proportions of epoxides and residual substrates (Tables 2 and 3), it was obvious that the sums were close to $100 \%$ with the mono- and diunsaturated substrates (ranging from $85.0 \%-98.8 \%$ with methyl esters and $97.6 \%-122.0 \%$ with 
401

402

403

404

405

406

407

408

409

410

411

412

413

414

fatty acids), but that they were much lower with triunsaturated substrates (ranging from 66.7\%$80.9 \%$ with methyl esters and $74.1 \%-90.8 \%$ with fatty acids). Therefore, it may be that oat POX is not selective in terms of the unsaturation level of the substrate. Earlier, an oat POX gene transferred and expressed in Pichia pastoris preferred oleic acid over other unsaturated fatty acids as the substrate, whereas the hydroperoxides of polyunsaturated fatty acids were better oxygen donors to the fatty acids than oleic acid hydroperoxide was (Meesapyodsuk et al., 2011), which might influence the reactions with natural oat lipids.

Observations regarding the selectivity of the products were undertaken for methyl linoleate and linoleic acid. Of the two epoxides built up from methyl linoleate and linoleic acid, there were more 12,13-epoxy compounds than 9,10-epoxy compounds, with values of $17.9 \% \pm 2.8 \%$ and $15.1 \% \pm$ $2.4 \%$ for methyl linoleate, and $29.9 \% \pm 3.5 \%$ and $28.1 \% \pm 3.1 \%$ for linoleic acid. The differences were not big, although they were statistically significant $\left(t_{71}=41.1, p<0.05\right.$ and $\left.t_{71}=9.7, p<0.05\right)$. This indicates that both epoxides are likely to be observed in comparable amounts in oat. Similarly, Piazza et al., (2003) reported the formation of an equal amount of mono 9,10-epoxy and 12,13epoxy octadecenoic acids, thus indicating that the oat POX cannot distinguish the double bonds in the substrate.

No epoxide formation could be found in any faba bean samples using methyl oleate, oleic acid or triolein as the substrate. Therefore, it was concluded that there was no POX activity or that the activity was very low in the faba bean samples.

\subsection{Differences in peroxygenase activity among oat cultivars and sample years}

There was a statistically significant difference in POX activities among oat cultivars $\left(F_{3.420}=6.2, p\right.$ $<0.05$ ) and the values could be clearly divided to produce two homogenous groups (Tukey HSD, $p$ 
$<0.05)$. Cultivars Akseli and Meeri belonged to the low POX activity group, with average values of $36.9 \% \pm 11.8 \%$ and $40.8 \% \pm 14.5 \%$, respectively. The cultivar Meeri also belonged to the high POX group, together with cultivars Alku and Steiner, with values of $43.8 \% \pm 14.6 \%$ and $44.1 \% \pm$ $15.2 \%$, respectively. The variation in these average values was large due to the many substrates, but the differences among the cultivars were clear. Epoxidation was always the lowest in cultivar Akseli with all substrates and also in every sample year except for one. Usually, cultivars Steinar and Meeri gave the highest amounts of epoxides and also the lowest residual substrate values. The average activity in cultivar Steiner was $20 \%$ greater than in Akseli. The sample year did not have a statistically significant effect on POX activities in the oat samples $\left(F_{2.420}=0.98, p>0.05\right)$ and nor was there an interaction between the cultivar and the sample year $\left(F_{6.420}=0.72, p>0.05\right)$. Yet a variation in the POX activities among sample years with individual substrates could be observed.

\subsection{Evaluation of the potential of lipid-modifying enzymes to cause off-flavours}

Based on the enzyme activities of three different lipid-modifying enzymes in oat and faba bean, a scheme on off-flavour formation was created (Fig. 4). This study showed that enzymatic activity to hydrolyse lipids occurs both in oat and in faba bean, which may start the lipid oxidation cascade. In oat, due to very low LOX activities, fatty acids are primarily subjected to autoxidation, yielding the formation of hydroperoxides and their further reactions. Anyhow, oxidation of oat lipids occurred much faster when its lipids were being hydrolysed by lipase (Lampi, Damerau, Moisio, Partanen, Forssell \& Piironen, 2015). Hydroperoxides of fatty acids are good substrates for oat POX, which could result in the production of epoxy and hydroxy fatty acids, and possible bitter off-flavours in oat products. Since lipid oxidation is initiated by autoxidation, the formation of epoxy and hydroxy fatty acids is not rapid and is more likely to occur when oat or oat products with enzyme activities are stored for longer periods. The high content of lipids and the degree of unsaturation in oat enhances the risk of the formation of epoxy and hydroxy compounds. The very high lipid- 
451 hydrolysing activity present in faba bean, subjects not only the lipids of the seeds, but also of other 452 lipids in the products, to the formation of FFAs. This should be taken into account when e.g. faba 453 bean emulsions are prepared. As the polyunsaturated fatty acids are substrates for faba bean LOX, 454 fatty acid hydroperoxides are built up rapidly and may decompose into volatile oxidation products 455 causing off-flavours. Thus, the so-called beany flavour may be observed rapidly after faba bean 456 flour is suspended in aqueous systems. It is likely that epoxy and hydroxy fatty acids are not as 457 important in terms of producing off-flavours in faba bean as they are in oat products due to the low 458 POX activity in faba bean. sample years were observed, but the differences were only modest and would probably not have major effects on off-flavour formation in oat and faba bean.

\section{Acknowledgements}

466 The authors would like to thank Miikka Olin for his skillful technical assistance on the instrument 467 analysis, Boreal Plant Breeding Ltd. for providing the oat samples and Frederick Stoddard for 468 providing the faba bean samples of the cultivars. We would also thank China Scholarship Council 469 for funding the Ph.D studies of Z. Yang. 
472 Brunschwiler, C., Heine, D., Kappeler, S., Conde-Petit, B., \& Nyström, L. (2013). Direct

473 measurement of rice bran lipase activity for inactivation kinetics and storage stability prediction.

474 Journal of Cereal Science, 58, 272-277.

475 Chang, P. R. Q., \& McCurdy, A. R. (1985). Lipoxygenase activity in flourteen legumes. Canadian 476 Institute of Food Science and Technology Journal, 18, 94-96.

477 Christie, W. W. (1993). Preparation of ester derivatives of fatty acids for chromatographic analysis.

478 In W. W. Christie (Ed.), Advances in lipid methodology - two (pp. 69-111). Dundee: Oily Press.

479 Christie, W. W. (2014). AOCS Lipid Library.

480 http://lipidlibrary.aocs.org/content.cfm?ItemNumber=39512. Updated March 11, 2014.

481 Clemente, A., Olías, R., \& Olías, J. M. (2000). Purification and characterization of broad bean 482 lipoxygenase isoenzymes. Journal of Agriculture and Food Chemistry, 48, 1070-1075.

483 Crépon, K., Marget, P., Peyronnet, C., Carrouee, B., Arese, P., \& Duc, G. (2010). Nutritional value 484 of faba bean (Vicia faba L.) seeds for feed and food. Field Crops Research, 115, 329-339.

485 Decker, E. A., Rose, D. J., \& Stewart, D. (2014). Processing of oats and the impact of processing 486 operations on nutrition and health benefits. British Journal of Nutrition, 112, S58-S64.

487 Doehlert, D. C., Angelikousis, S., \& Vick, B. (2010). Accumulation of oxygenated fatty acids in oat 488 lipids during storage. Cereal Chemistry, 87, 532-537.

489 Dundas, D. G. A., Henderson, H. M., \& Eskin, N. A. M. (1978). Lipase from Vicia faba minor. 490 Food Chemistry, 3, 171-178.

491 Ekstrand, B., Gangby, I., \& Åkesson, G. (1992). Lipase activity in oats - distribution, pH 492 dependence, and heat inactivation. Cereal Chemistry, 69(4), 379-381.

493 Gardner, H. W. (2003). Lipoxygenase and associated enzymes. In J. R. Whitaker, A. G. J. Voragen, 494 \& D. W. S. Wong (Eds.), Handbook of Food Enzymology (pp. 557-567). New York: Marcel 495 Dekker, Inc. 
496 Gökmen, V., Bahceci, S., \& Acar, J. (2002). Characterization of crude lipoxygenase extract from

497

498

499

500

501

502

503

504

505

506

507

508

509

510

511

512

513

514

515

516

517

518

519

green pea using a modified spectrophotometric method. European Food Research and Technology, $215,42-45$.

Hamberg, M., \& Fahlstadius, P. (1992). On the specificity of a fatty acid epoxygenase in broad bean

(Vicia faba L.). Plant Physiology, 99, 987-995.

Hamberg, M., \& Hamberg, G. (1996). Peroxygenase-Catalyzed Fatty Acid Epoxidation in Cereal Seeds (Sequential Oxidation of Linoleic Acid into 9(S),12(S),13(S)-Trihydroxy-10(E)-

Octadecenoic Acid). Plant Physiology, 110, 807-815.

Henderson, H. M., Shambrock, D. L., \& Eskin, N. A. M. (1981). The enzymic deacylation of $p$ nitrophenyl esters and phosphatidylcholine in vicia faba minor. Food Chemistry, 7(4), 249-256.

Hildebrand, D. F., \& Kito, M. (1984). Role of lipoxygenases in soybean seed protein quality.

Journal of Agriculture and Food Chemistry, 32, 815-819.

Hu, X. Z., Wei, Y. M., Ren, C. Z., \& Zhao, J. (2009). Relationship between kernel size and shape and lipase activity of naked oat before and after pearling treatment. Journal of the Science of Food and Agriculture, 89, 1424-1427.

Jiang, Z. Q., Pulkkinen, M., Wang, Y. J., Lampi, A. M., Stoddard, F. L., Salovaara, H., Piironen, V., \& Sontag-Strohm, T. (2016). Faba bean flavour and technological property improvement by thermal pre-treatments. LWT - Food Science and Technology, 68, 295-305.

Lampi, A.-M., Damerau, A., Li, J., Moisio, T., Partanen, R., Forssell, P., \& Piironen, V. (2015).

Changes in lipids and volatile compounds of oat flours and extrudates during processing and storage. Journal of Cereal Science, 62, 102-109.

Lehtinen, P., Kaukovirta-Norja, A. (2011). Oat lipids, enzymes, and quality. F. H. Webster, \& P. J. Wood (Eds.), Oats: Chemistry and Technology, Second Edition (pp. 143-156). St. Paul: AACC International, Int. 
Lehtinen, P., Kiiliäinen, K., Lehtomäki, I., \& Laakso, S. (2003). Effect of Heat Treatment on Lipid Stability in Processed Oats. Journal of Cereal Science, 37(2), 215-221.

Lizarazo, C. I., Lampi, A. M., Liu, J., Sontag-Strohm, T., Piironen, V., \& Stoddard, F. L. (2015).

Nutritive quality and protein production from grain legumes in a boreal climate. Journal of the Science of Food and Agriculture, 95(10), 2053-2064.

Meesapyodsuk, D., Qiu, X. (2011). A peroxygenase pathway involved in the biosynthesis of epoxy fatty acids in oat. Plant Physiology, 157, 454-463.

Miller, S. S., Fulcher, R. G., \& Altosaar, I. (1989). Evaluation of 4-methylumbelliferyl heptanoate as a substrate for oat lipase. Journal of Cereal Science, 10, 61-68.

Murphy, R. C. (2015). Tandem Mass Spectrometry of Lipids: Molecular Analysis of Complex Lipids. Cambridge: Royal Society of Chemistry, (Chapter 1).

Orellana-Coca, C., Adlercreutz, D., Andersson, M. M., Mattiasson, B., \& Hatti-Kaul, R. (2005). Analysis of fatty acid epoxidation by high performance liquid chromatography coupled with evaporative light scattering detection and mass spectrometry. Chemistry and Physics of Lipids, 135, 189-199.

Piazza, G. J., Bilyk, A., Brower, D. P., \& Haas, M. J. (1992). The positional and fatty acid selectivity of oat seed lipase in aqueous emulsions. Journal of the American Oil Chemists' Society, 69, 978-981.

Piazza, G. J., Nuñez, A., \& Foglia, T. A. (2003). Epoxidation of fatty acids, fatty methyl esters, and alkenes byimmobilized oat seed peroxygenase. Journal of Molecular Catalysis B: Enzymatic, 21, 143-151.

Roland, W. S. U., Pouvreau, L., Curran, J., van de Velde, F., \& de Kok, P. M. T. (2017). Flavor aspects of pulse ingredients. Cereal Chemistry, 94, 58-65. 


\section{Figure Legends}

545 Fig. 1. Lipase and LOX activities in oat and faba bean samples from four cultivars in different 546 cultivation years ( 2 extracts x 3 measurements; $n=6$ ): (a) lipase activity in oat; (b) lipase activity in faba bean; and (c) LOX activity in faba bean.

Fig. 2. Combined GC-FID chromatograms of methyl oleate, methyl linoleate, and methyl linolenate after incubation with oat extracts containing POX and formation of epoxides. Where, $1=$ methyl oleate, 2 = methyl linoleate, 3 = methyl nonadecanoic acid (internal standard), $4=$ methyl linolenate, 5 = methyl 9,10-epoxyoctadecanoate, $6=$ methyl 12,13-epoxy-octadec-9-enoate, $7=$ methyl 9,10-epoxy-octadec-12-enoate and $8=$ epoxides produced from methyl linolenate.

Fig. 3. Combined UHPLC-ELSD chromatograms of oleic acid, linoleic acid, and linolenic acid after incubation with oat extracts containing POX and formation of epoxides. Where, $1=$ epoxides produced from linolenic acid, 2 = 12,13-epoxy-9-octadecenoic acid, 3 = 9,10-epoxy-12octadecenoic acid, $4=\left(\right.$ trans $\left.{ }^{-}\right)$9,10-epoxystearic acid, $5=$ linolenic acid, $6=$ linoleic acid, $7=$ oleic acid and $8=$ nonadecanoic acid (internal standard).

Fig. 4. The most probable enzymatic and chemical reactions to cause potential off-flavour compounds from lipids in a) oat and b) faba bean. 


\section{Table legends}

Table 1. Identification of the epoxides formed from a) fatty acid methyl esters and b) fatty acids, during incubation with oat extracts containing POX from using GC-MS analysis for fatty acid methyl esters, and UHPLC-Q-TOF for free fatty acids.

Table 2. Proportions of epoxidation products ${ }^{\S}$ and substrate residues ${ }^{\#}$ of the three unsaturated fatty acid methyl esters incubated with oat extracts containing POX from four oat cultivar samples from different years $(n=6)$.

${ }^{\S}$ Proportions (\%) of epoxides from methyl oleate: methyl 9,10-epoxyoctadecanoate; from methyl linoleate: $1=$ methyl 12,13-epoxy-octadec-9-enoate and 2: methyl 9,10epoxy-octadec-12-enoate; and methyl linolenate: a mixture of methyl mono-epoxyoctadecadienoates.

\# Proportions (\%) of fatty acid methyl esters left after incubation.

Table 3. Proportions of epoxidation products ${ }^{\S}$ and substrate residues ${ }^{\#}$ of the three unsaturated fatty acids incubated with oat extracts containing POX from four oat cultivar samples from different years $(n=6)$.

${ }^{\S}$ Proportions (\%) of epoxides from oleic acid: 9,10-epoxyoctadecanoic acid; from linoleic acid: 1= 12,13-epoxy-octadec-9-enoic acid and 2: 9,10-epoxy-octadec-12enoic acid; and linolenic acid: a mixture of mono-epoxy-octadecadienoic acids.

\# Proportions (\%) of fatty acids left after incubation. 
Figure 1.
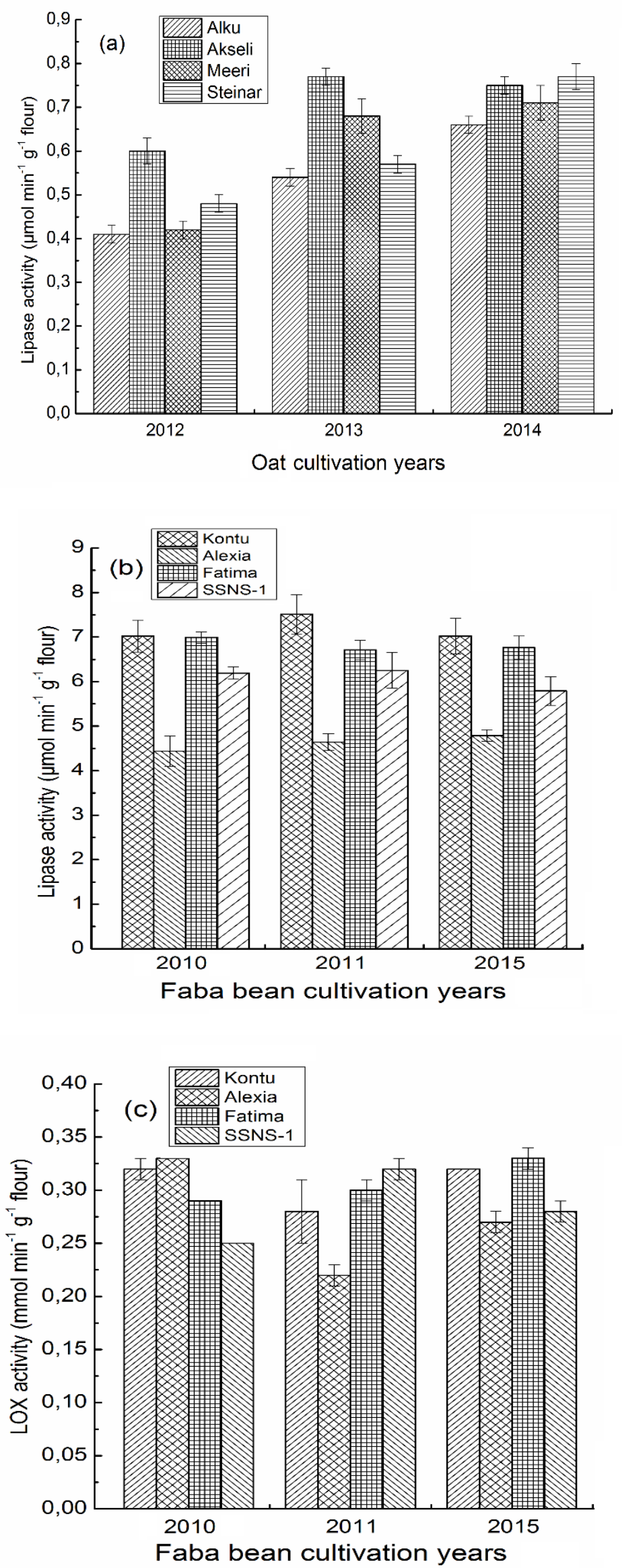
Figure 2.

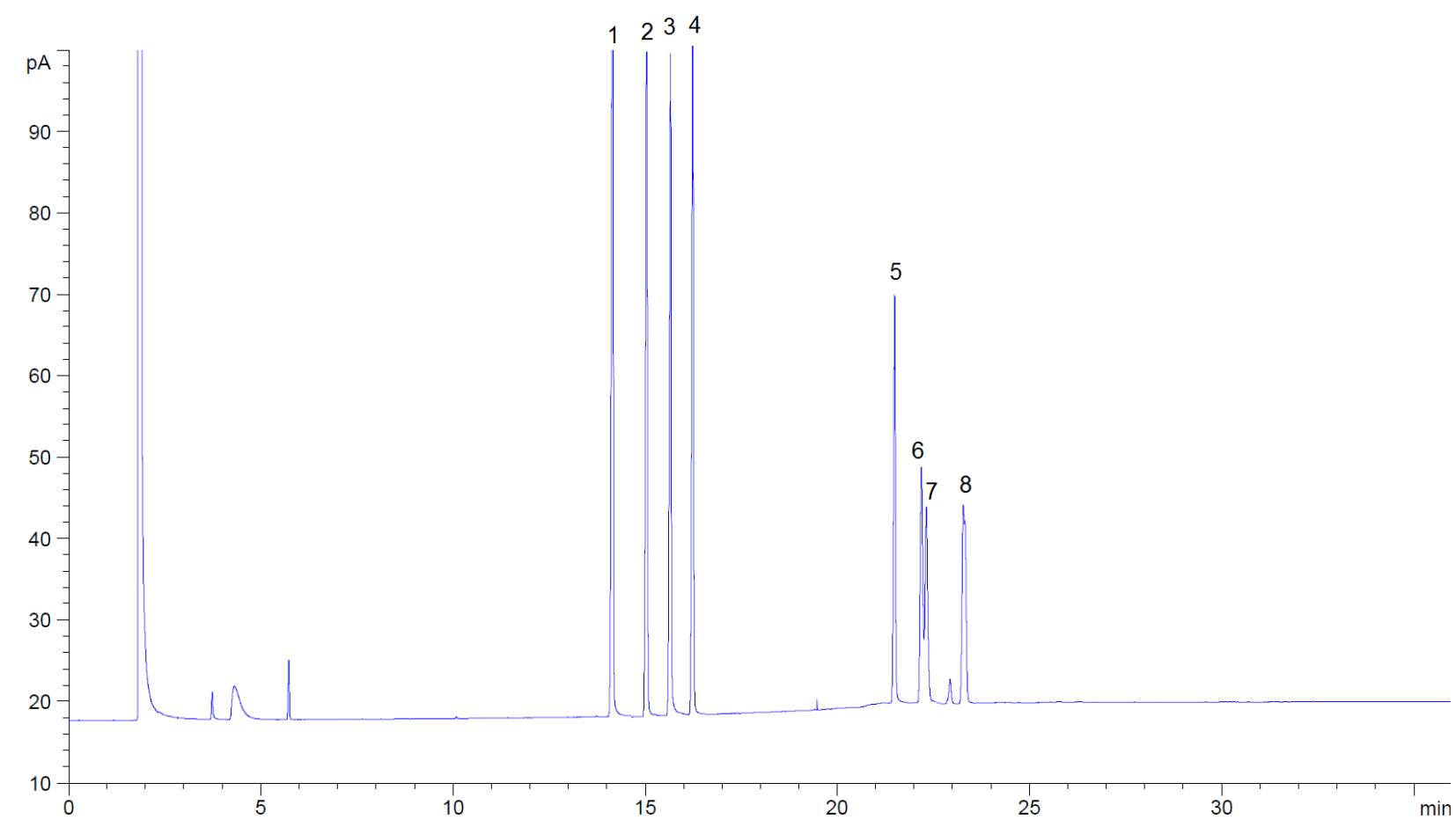


Figure 3.

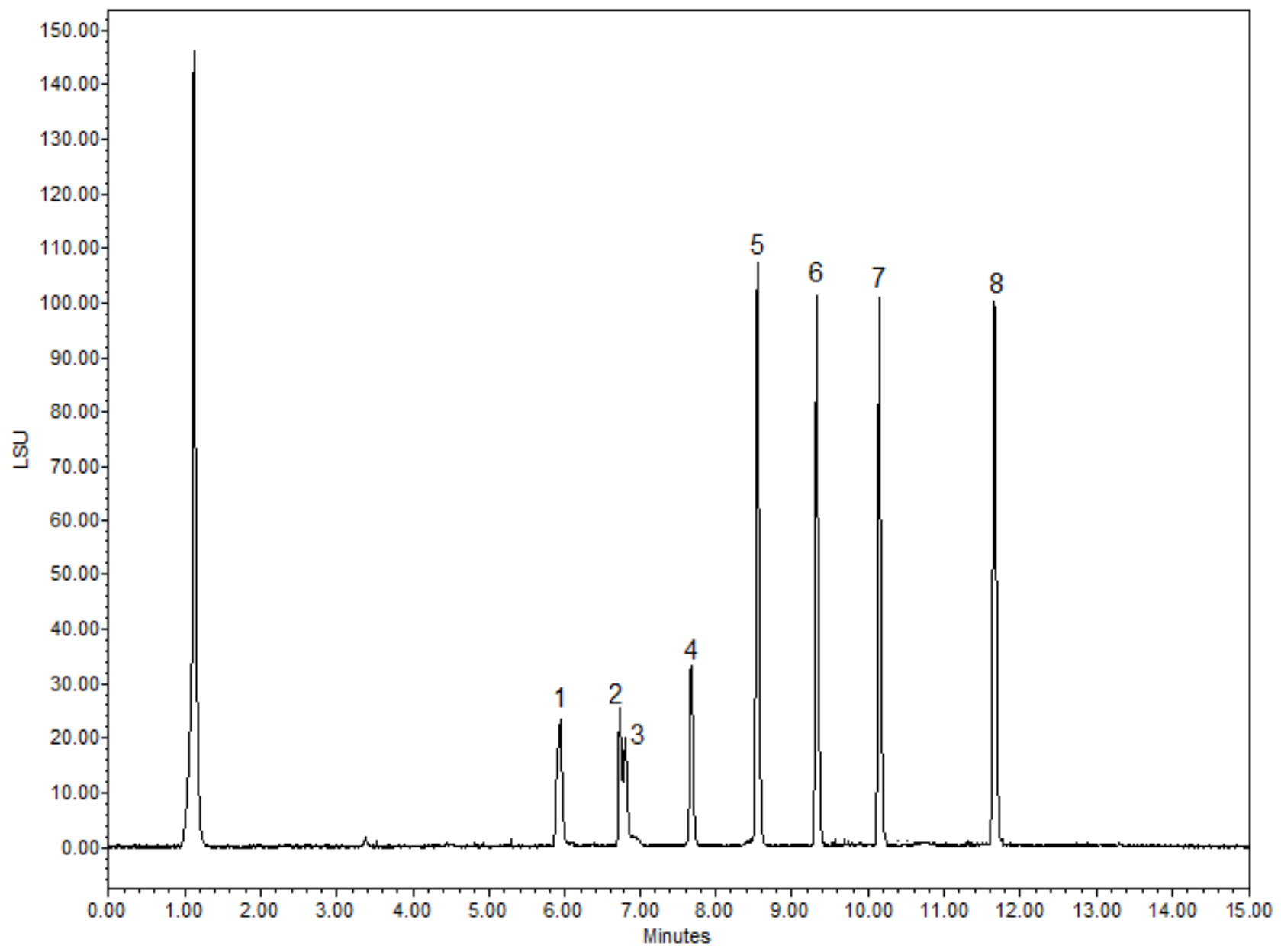


Figure 4.

a) Oat

$$
\text { Lipase }
$$

TAG

Unsaturated fatty acids

Autoxidation

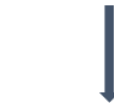

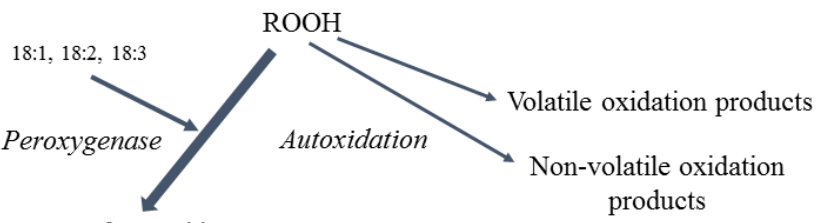

b) Faba bean

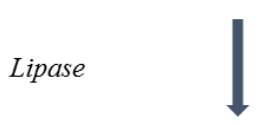

Polyunsaturated fatty acids

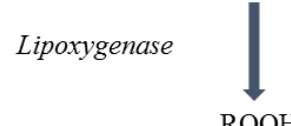

Autoxidation
$\begin{aligned} & \text { Hydroperoxide degrading } \\ & \text { enzymes }\end{aligned}$
$\begin{gathered}\text { Non-volatile oxidation products } \\ \text { products }\end{gathered}$

Epoxy fatty acids

Hydroxy fatty acids 
Table 1.

Table 1a)

\begin{tabular}{|c|c|c|c|c|c|c|}
\hline \multirow{2}{*}{$\begin{array}{l}\text { Fatty acid } \\
\text { methyl ester } \\
\text { epoxide }\end{array}$} & \multirow{2}{*}{$\begin{array}{c}\mathbf{R}_{\mathbf{r}}: \\
t_{\text {epoxide }} / \\
t_{\text {19:0me }}\end{array}$} & \multirow{2}{*}{$\begin{array}{l}\text { Molecular } \\
\text { ion } M^{+} \\
(m / z)\end{array}$} & \multicolumn{3}{|c|}{ Fragment ions $(\mathrm{m} / \mathrm{z})$ formed from cleavage of } & \multirow{2}{*}{$\begin{array}{c}\text { Other } \\
\text { fragment ions } \\
(m / z)\end{array}$} \\
\hline & & & the methanol group & $\alpha$ C-C bol & I next to the epoxide & \\
\hline $\begin{array}{l}\text { me-9,10-epoxy- } \\
\text { octadecanoate }\end{array}$ & 1.332 & 312 & & $\begin{array}{l}\text { 155; [M-157] } \\
\bullet\left(\mathrm{CH}_{2}\right)_{7} \mathrm{COOCH}_{3}\end{array}$ & $199 ;[\mathrm{M}-113] \bullet\left(\mathrm{CH}_{2}\right)_{7} \mathrm{CH}_{3}$ & 171 \\
\hline $\begin{array}{l}\text { me-12,13-epoxy- } \\
\text { octadec-9-enoate }\end{array}$ & 1.354 & 310 & $279 ;[\mathrm{M}-31] \bullet \mathrm{OCH}_{3}$ & $\begin{array}{l}164 ;[\mathrm{M}-146] \\
\mathrm{C}_{7} \mathrm{OH}_{15} \text { and } \bullet \mathrm{OCH}_{3}\end{array}$ & $\begin{array}{l}\text { 207; }[\mathrm{M}-103] \mathrm{CH}_{3}\left(\mathrm{CH}_{2}\right)_{3} \mathrm{CH}_{3} \\
\text { and } \bullet \mathrm{OCH}_{3}\end{array}$ & $\begin{array}{l}121,136,149, \\
166\end{array}$ \\
\hline $\begin{array}{l}\text { me-9,10-epoxy- } \\
\text { octadec-12-enoate }\end{array}$ & 1.361 & 310 & $279 ;[\mathrm{M}-31] \bullet \mathrm{OCH}_{3}$ & & $\begin{array}{l}168 ;[\mathrm{M}-142] \\
\mathrm{C}_{8} \mathrm{H}_{15} \text { and } \bullet \mathrm{OCH}_{3}\end{array}$ & $\begin{array}{l}121,133,150 \\
155,185\end{array}$ \\
\hline $\begin{array}{l}\text { me-epoxy- } \\
\text { octadecadienoate }\end{array}$ & 1.423 & 308 & $277 ;[\mathrm{M}-31] \bullet \mathrm{OCH}_{3}$ & & & $\begin{array}{l}121,133,135 \\
155,207,236\end{array}$ \\
\hline
\end{tabular}


Table 1b)

\begin{tabular}{|c|c|c|c|c|c|c|}
\hline \multirow{4}{*}{ Fatty acid epoxide } & \multirow{4}{*}{$\begin{array}{l}\mathbf{R}_{\mathbf{r}}: \\
\mathbf{t}_{\text {epoxide }} / \\
\mathbf{t}_{19: 0}\end{array}$} & \multirow{4}{*}{$\begin{array}{l}\text { Precursor } \\
\text { ion } \\
{[M-H]^{-}} \\
(m / z)\end{array}$} & \multicolumn{4}{|c|}{ Fragment ions $(m / z)$ formed from } \\
\hline & & & \multirow{3}{*}{$\begin{array}{l}\text { Loss of } \\
\mathrm{H}_{2} \mathrm{O}\end{array}$} & \multicolumn{3}{|c|}{$\begin{array}{l}\text { Homolytic cleavage of the epoxidic C-O bond followed by scission of the } \\
\text { C-C bond }\end{array}$} \\
\hline & & & & \multicolumn{2}{|c|}{$\begin{array}{l}\text { of the epoxide on the side of } \\
\text { fatty acid }\end{array}$} & \multirow[t]{2}{*}{$\begin{array}{l}\text { on the side of the } \gamma \text {-double bond after } \\
\text { hydrogen atom rearrangement }\end{array}$} \\
\hline & & & & $-\mathrm{COO}^{-}$ & $-\mathrm{CH}_{3}$ & \\
\hline $\begin{array}{l}9,10 \text { epoxy- } \\
\text { octadecanoic acid }\end{array}$ & 0.649 & 297.2 & 279.2 & 155.1 & 171.1 & \\
\hline $\begin{array}{l}\text { 12,13-epoxy-octadec- } \\
\text { 9-enoic acid }\end{array}$ & 0.575 & 295.2 & 277.2 & 195.1 & & 183.1 \\
\hline $\begin{array}{l}\text { 9,10-epoxy-octadec- } \\
\text { 12-enoic acid }\end{array}$ & 0.581 & 295.2 & 277.2 & & 171.1 & 183.1 \\
\hline $\begin{array}{l}9,10 \text {-epoxy- } 12,15 \text { - } \\
\text { octadeca-dienoic acid }\end{array}$ & 0.532 & 293.2 & 275.2 & & 171.1 & 183.1 \\
\hline $\begin{array}{l}\text { 15,16-epoxy-9,12- } \\
\text { octadeca-dienoic acid }\end{array}$ & 0.537 & 293.2 & 275.2 & 235.2 & & 223.2 \\
\hline $\begin{array}{l}\text { 12,13-epoxy-9,15- } \\
\text { octadeca-dienoic acid }\end{array}$ & 0.549 & 293.2 & 275.2 & 195.1 & 211.1 & $223.1 ; 183.1$ \\
\hline
\end{tabular}


Table 2.

\begin{tabular}{|c|c|c|c|c|c|c|c|}
\hline \multirow{3}{*}{$\begin{array}{c}\text { Oat Samples } \\
\text { Year } 2012\end{array}$} & \multicolumn{7}{|c|}{ Fatty acid methyl ester substrates } \\
\hline & \multicolumn{2}{|c|}{ me-oleate (\%) } & \multicolumn{3}{|c|}{ me-linoleate $(\%)$} & \multicolumn{2}{|c|}{ me-linolenate (\%) } \\
\hline & Epoxide $^{\S}$ & Residue $^{\#}$ & Epoxide $1^{\S}$ & Epoxide $2^{\S}$ & Residue $^{\#}$ & Epoxides $^{\S}$ & Residue $^{\#}$ \\
\hline $\mathrm{Alku}$ & $36.2 \pm 0.5$ & $59.4 \pm 0.3$ & $18.9 \pm 0.1$ & $16.3 \pm 0.1$ & $50.1 \pm 0.3$ & $25.7 \pm 0.4$ & $44.8 \pm 2.0$ \\
\hline Akseli & $19.5 \pm 0.3$ & $78.2 \pm 0.7$ & $11.9 \pm 0.3$ & $10.4 \pm 0.2$ & $67.0 \pm 0.7$ & $24.1 \pm 0.2$ & $49.1 \pm 0.5$ \\
\hline Steinar & $38.3 \pm 0.4$ & $56.1 \pm 0.2$ & $20.1 \pm 0.0$ & $17.1 \pm 0.1$ & $49.7 \pm 0.1$ & $25.5 \pm 0.3$ & $46.6 \pm 0.5$ \\
\hline Meeri & $38.2 \pm 1.2$ & $57.6 \pm 1.7$ & $20.9 \pm 0.0$ & $17.7 \pm 0.1$ & $48.0 \pm 0.4$ & $26.5 \pm 0.3$ & $44.3 \pm 0.7$ \\
\hline \multicolumn{8}{|l|}{ Year 2013} \\
\hline Alku & $35.0 \pm 1.7$ & $60.6 \pm 2.4$ & $19.0 \pm 0.3$ & $15.8 \pm 0.3$ & $53.0 \pm 0.8$ & $20.6 \pm 0.3$ & $50.4 \pm 1.1$ \\
\hline Akseli & $27.9 \pm 1.1$ & $69.2 \pm 0.9$ & $15.2 \pm 0.2$ & $12.7 \pm 0.2$ & $62.3 \pm 0.2$ & $22.2 \pm 0.6$ & $51.6 \pm 0.5$ \\
\hline Steinar & $41.6 \pm 0.4$ & $54.0 \pm 0.3$ & $21.8 \pm 0.5$ & $18.7 \pm 0.5$ & $46.7 \pm 0.4$ & $22.6 \pm 0.6$ & $44.7 \pm 1.0$ \\
\hline Meeri & $29.6 \pm 0.7$ & $67.3 \pm 0.3$ & $17.1 \pm 0.2$ & $14.8 \pm 0.2$ & $59.1 \pm 1.1$ & $23.0 \pm 0.5$ & $49.4 \pm 1.0$ \\
\hline \multicolumn{8}{|l|}{ Year 2014} \\
\hline Alku & $30.1 \pm 0.4$ & $67.8 \pm 0.8$ & $16.0 \pm 0.3$ & $13.3 \pm 0.2$ & $61.6 \pm 0.8$ & $23.5 \pm 0.6$ & $54.0 \pm 1.4$ \\
\hline Akseli & $24.2 \pm 0.3$ & $74.2 \pm 0.7$ & $15.0 \pm 0.2$ & $12.4 \pm 0.2$ & $63.8 \pm 0.7$ & $22.1 \pm 0.8$ & $58.0 \pm 0.4$ \\
\hline Steinar & $33.3 \pm 0.4$ & $60.9 \pm 0.2$ & $19.6 \pm 0.2$ & $15.9 \pm 0.1$ & $54.2 \pm 0.7$ & $23.2 \pm 0.7$ & $51.2 \pm 0.8$ \\
\hline Meeri & $35.8 \pm 0.4$ & $58.3 \pm 0.2$ & $19.7 \pm 0.3$ & $16.1 \pm 0.2$ & $52.5 \pm 0.2$ & $24.4 \pm 1.0$ & $51.0 \pm 1.3$ \\
\hline Total & $32.5 \pm 6.2$ & $63.6 \pm 7.4$ & $17.9 \pm 2.8$ & $15.1 \pm 2.4$ & $55.7 \pm 6.6$ & $23.6 \pm 1.7$ & $49.6 \pm 4.1$ \\
\hline
\end{tabular}


Table 3.

\begin{tabular}{c|cc|ccc|cc}
\hline \multirow{2}{*}{ Oat Samples } & \multicolumn{7}{c}{ Free fatty acid substrates } \\
\cline { 2 - 7 } Oleic acid (\%) & \multicolumn{3}{c}{ Linoleic acid (\%) } & \multicolumn{2}{c}{ Linolenic acid (\%) } \\
\hline Year 2012 & Epoxide $^{\S}$ & Residue $^{\#}$ & Epoxide 1 & Epoxide 2 & Residue $^{\S}$ & Epoxides $^{\S}$ & Residue $^{\sharp}$ \\
Alku & $67.5 \pm 1.3$ & $44.3 \pm 1.1$ & $34.1 \pm 1.0$ & $32.0 \pm 1.2$ & $37.5 \pm 0.7$ & $45.8 \pm 1.4$ & $37.4 \pm 1.8$ \\
Akseli & $56.8 \pm 2.2$ & $59.3 \pm 2.5$ & $26.6 \pm 0.2$ & $23.7 \pm 0.7$ & $51.7 \pm 1.8$ & $38.9 \pm 0.8$ & $48.2 \pm 1.5$ \\
Steinar & $63.5 \pm 1.2$ & $50.7 \pm 0.8$ & $32.9 \pm 0.7$ & $30.0 \pm 1.0$ & $43.7 \pm 0.9$ & $42.9 \pm 1.2$ & $43.2 \pm 0.6$ \\
Meeri & $64.0 \pm 1.5$ & $50.3 \pm 0.6$ & $30.4 \pm 0.9$ & $29.0 \pm 0.7$ & $42.5 \pm 1.0$ & $43.0 \pm 0.7$ & $42.5 \pm 0.7$ \\
Year 2013 & & & & & & \\
Alku & $60.4 \pm 1.6$ & $48.3 \pm 1.2$ & $31.2 \pm 1.2$ & $30.3 \pm 0.4$ & $43.5 \pm 0.8$ & $43.3 \pm 0.6$ & $37.8 \pm 0.8$ \\
Akseli & $51.9 \pm 2.3$ & $59.8 \pm 1.1$ & $24.4 \pm 1.4$ & $23.9 \pm 0.5$ & $53.1 \pm 0.5$ & $35.8 \pm 0.9$ & $47.4 \pm 1.5$ \\
Steinar & $67.4 \pm 0.6$ & $42.1 \pm 1.4$ & $35.2 \pm 0.7$ & $32.3 \pm 1.5$ & $37.7 \pm 1.0$ & $47.1 \pm 1.6$ & $37.5 \pm 0.6$ \\
Meeri & $56.2 \pm 1.2$ & $55.8 \pm 0.9$ & $26.7 \pm 0.2$ & $26.4 \pm 0.7$ & $50.6 \pm 0.9$ & $39.9 \pm 1.8$ & $47.1 \pm 1.2$ \\
Year 2014 & & & & & & \\
Alku & $58.2 \pm 1.3$ & $49.4 \pm 3.1$ & $30.5 \pm 1.3$ & $28.3 \pm 0.9$ & $44.0 \pm 1.1$ & $43.2 \pm 1.7$ & $43.3 \pm 1.5$ \\
Akseli & $50.7 \pm 2.9$ & $59.4 \pm 2.2$ & $24.9 \pm 1.1$ & $23.8 \pm 1.1$ & $53.8 \pm 0.9$ & $35.8 \pm 1.2$ & $48.6 \pm 1.1$ \\
Steinar & $60.9 \pm 1.1$ & $46.8 \pm 1.0$ & $30.3 \pm 1.0$ & $28.1 \pm 0.8$ & $43.0 \pm 0.4$ & $39.7 \pm 1.1$ & $35.8 \pm 0.6$ \\
Meeri & $61.1 \pm 1.1$ & $43.4 \pm 1.4$ & $31.8 \pm 0.9$ & $29.2 \pm 1.0$ & $39.0 \pm 1.0$ & $41.0 \pm 1.0$ & $36.1 \pm 1.1$ \\
Total & $59.9 \pm 5.4$ & $50.8 \pm 6.3$ & $29.9 \pm 3.5$ & $28.1 \pm 3.1$ & $45.0 \pm 5.7$ & $41.4 \pm 3.6$ & $42.1 \pm 4.9$ \\
\hline
\end{tabular}

